\title{
Equilibrium high-temperature Fe isotope fractionation between fayalite and magnetite: An experimental calibration
}

\author{
Anat Shahar ${ }^{\mathrm{a}, *}$, Edward D. Young ${ }^{\mathrm{a}, \mathrm{b}}$, Craig E. Manning ${ }^{\mathrm{a}}$ \\ ${ }^{a}$ Department of Earth \& Space Sciences, University of California, Los Angeles, CA 90095 USA \\ ${ }^{\mathrm{b}}$ Institute of Geophysics and Planetary Physics, University of California, Los Angeles, CA 90095 USA
}

Received 20 October 2007; received in revised form 14 January 2008; accepted 17 January 2008 Available online 6 February 2008

Editor: R.W. Carlson

\begin{abstract}
The iron isotopic fractionation factor between magnetite and fayalite was measured at high temperature in a piston-cylinder apparatus. For the first time, the three-isotope method [Matsuhisa, J., Goldsmith, J. R., and Clayton, R. N., 1978. Mechanisms of hydrothermal crystallisation of quartz at $250{ }^{\circ} \mathrm{C}$ and $15 \mathrm{kbar}$. Geochim. Cosmochim. Acta 42, 173-182.] has been used to determine equilibrium fractionation between two minerals directly. The experimentally-determined temperature-dependent iron isotope fractionation between fayalite and magnetite is described by $10^{3} \ln \alpha^{57}{ }_{\mathrm{Mag}-\mathrm{Fa}} \cong \Delta^{57} \mathrm{Fe}_{\mathrm{Mag}-\mathrm{Fa}}=0.30(+/-0.024) \times 10^{6} / T^{2}$. The equation predicts measurable fractionation at magmatic temperatures. Our work bears on the magnitude of $\mathrm{Fe}$ isotope fractionation attending differentiation in magmatic systems and provides a new isotope thermometer for coexisting fayalite and magnetite.
\end{abstract}

(C) 2008 Elsevier B.V. All rights reserved.

Keywords: iron isotope; thermometer; igneous rocks; high-temperature; three-isotope exchange; magnetite

\section{Introduction}

Iron isotope ratios have proven to be especially useful tracers in a variety of geochemical settings due to the ubiquitous nature of $\mathrm{Fe}$ and to its variable oxidation states. Differences in iron isotope ratios have been used to address a myriad of questions including, but not limited to, those relating to: biosignatures (Beard and Johnson, 1999), early solar system processes (Zhu et al., 2001), and planet formation processes (Poitrasson et al., 2004). Each of these applications depends critically on understanding factors that fractionate $\mathrm{Fe}$ isotopes.

Most work involving $\mathrm{Fe}$ isotopes has focused on lowtemperature processes because differences between minerals equilibrated at high temperature are expected to be small due to decreasing fractionation with increasing temperature $(T)$. But, with the advent of the multiple-collector inductively coupled plasma-source mass spectrometer (MC-ICPMS), these smaller

\footnotetext{
* Corresponding author.

E-mail address: ashahar@ess.ucla.edu (A. Shahar).
}

differences in $\delta^{56} \mathrm{Fe}$ and $\delta^{57} \mathrm{Fe}^{(1)}$ can now be measured more precisely.

Differences between $\delta^{56(57)} \mathrm{Fe}$ values of mantle minerals have been measured, but no consensus has been reached as to whether there are consistent iron isotopic fractionations amongst them. Zhu et al. (2002) found that olivine separates from lherzolites are isotopically lighter (by $>0.2 \%$ in ${ }^{57} \mathrm{Fe} /{ }^{54} \mathrm{Fe}$ ) than co-existing orthopyroxene and clinopyroxene. Beard and Johnson (2004) found that olivine and orthopyroxene separates from spinel peridotites have indistinguishable ${ }^{57} \mathrm{Fe} /{ }^{54} \mathrm{Fe}$, whereas co-existing clinopyroxene and olivine were found to show some measurable differences in $\delta^{57} \mathrm{Fe}$. A compilation of $\Delta^{56} \mathrm{Fe}_{\text {mineral-olivine }}\left(\Delta^{56} \mathrm{Fe}_{i-j}=\delta^{56} \mathrm{Fe}_{i}-\delta^{56} \mathrm{Fe}_{j}\right)$ representing separates of co-existing minerals in igneous rocks (Williams et al.,

\footnotetext{
$\overline{{ }^{1} \delta^{56(57)} \mathrm{Fe}}=\left({ }^{56(57)} \mathrm{R}_{\text {smp }} /{ }^{56(57)} \mathrm{R}_{\text {IRMM- } 014}-1\right) * 1000$ where ${ }^{56(57)} \mathrm{R}={ }^{56(57)} \mathrm{Fe} /{ }^{54} \mathrm{Fe}$ and IRMM-014 is an international Fe standard. In what follows reference will be made to both $\delta^{56} \mathrm{Fe}$ and $\delta^{57} \mathrm{Fe}$ since both values are reported by various authors. In all cases considered here Fe isotope fractionation is mass dependent and so there is no significance to choosing one ratio over the other.
} 
2005; Beard and Johnson, 2004; Zhu et al., 2002) is shown in Fig. 1. The plot underscores the fact that there are no clear systematic inter-mineral relationships emerging from the studies thus far. The peaks for the fractionations between olivine $(\mathrm{Ol})$ and clinopyroxene (Cpx), orthopyroxene (Opx), spinel (Spl), and magnetite (Mag) all overlap, with no mineral defining a population that is clearly resolvable from olivine. Calculations of bond strength predict that magnetite and spinel should concentrate ${ }^{56} \mathrm{Fe}$ and ${ }^{57} \mathrm{Fe}$ relative to ${ }^{54} \mathrm{Fe}$ more than co-existing silicate minerals because of the lower Fe coordination in the spinel-group minerals (Polyakov and Mineev, 2000). Of the minerals presented in Fig. 1, magnetite should show the largest difference from olivine due to its crystal chemistry and yet the magnetite data are centered on $\Delta^{56} \mathrm{Fe}_{\mathrm{Mag}-\mathrm{Ol}}=0$.

One explanation for a lack of a clear trend in Fig. 1 may be that differentiation processes are accompanied by $\mathrm{Fe}$ isotope fractionation, resulting in variable mineral ${ }^{56} \mathrm{Fe} /{ }^{54} \mathrm{Fe}$ values that reflect not only equilibrium mineral fractionation, but differences in bulk rock $\mathrm{Fe}$ isotope ratios from open-system processes. In the absence of direct experimental determination of Fe isotope fractionation factors it is not possible to determine what causes the lack of systematics among mantle igneous minerals shown in Fig. 1.

Understanding the equilibrium inter-mineral ${ }^{57} \mathrm{Fe} /{ }^{54} \mathrm{Fe}$ (and ${ }^{56} \mathrm{Fe} /{ }^{54} \mathrm{Fe}$ ) differences amongst high-temperature minerals should be valuable for interpretations of the significance of iron isotope ratios in igneous rocks, especially at the sub-\%o level currently being investigated. Ab initio predictions for $\mathrm{Fe}$ isotope fractionation among high- $T$ minerals exist, but experiments will ultimately be required to verify predictions, and in some cases to supplant them. To date there have been just two published high-temperature iron isotope experimental studies. Roskosz et al. (2006) investigated the kinetic fractionation of iron isotopes between a silicate melt and metal alloys at high temperature and room pressure. Schuessler et al. (2007) reported the iron isotopic fractionation factor between pyrrhotite and silicate melt at high pressure and temperature.

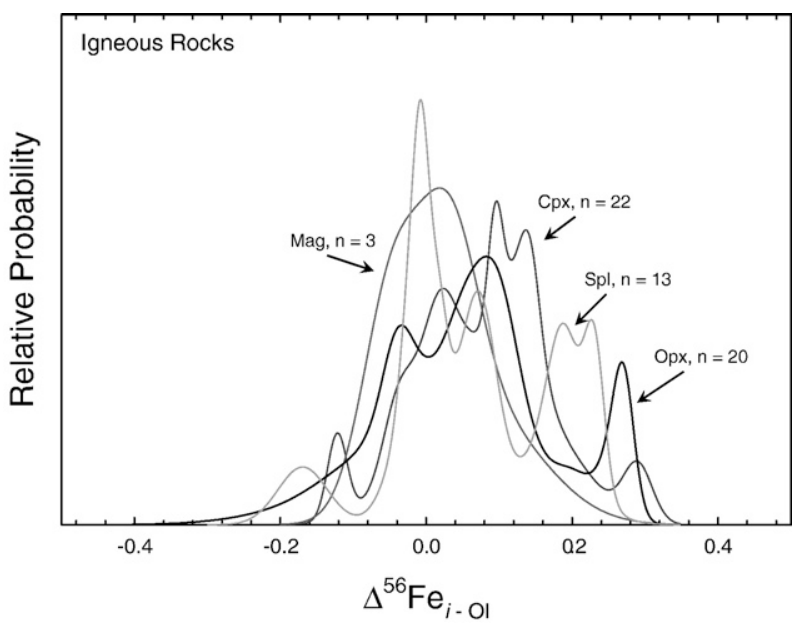

Fig. 1. Relative probability plot showing $\Delta^{56} \mathrm{Fe}_{\text {mineral-olivine }}$ in natural igneous rocks. Data compiled from Williams et al. (2005), Beard and Johnson (2004), and Zhu et al. (2002).
In this study we use the three-isotope exchange method (originally used for oxygen by Matsuhisa et al., 1978) to experimentally determine the equilibrium iron isotope fractionation factor between fayalite and magnetite as a function of temperature in the assemblage magnetite + quartz + fayalite $(\mathrm{Fa})$ comprising the "QFM" oxygen fugacity buffer. This study is a first step in experimentally quantifying inter-mineral $\mathrm{Fe}$ isotope fractionation in natural samples at high temperatures and known oxygen fugacity. Our results demonstrate that igneous differentiation involving magnetite, and by extension other spinel phases with tetrahedrally coordinated $\mathrm{Fe}$, can result in shifts in igneous rock $\mathrm{Fe}$ isotope ratios. They also provide a wellcalibrated $\mathrm{Fe}$ isotope thermometer for magnetite-fayalite-bearing rocks in equilibrium.

\section{Methods}

\subsection{Piston-cylinder experiments}

Starting materials were finely ground powders of synthetic, high-purity fayalite, quartz, and hematite. The fayalite and quartz were synthesized hydrothermally. Hematite was prepared by mixing $\alpha-\mathrm{Fe}_{2} \mathrm{O}_{3}$ powder (Alfa Aesar) with high-purity $\alpha-{ }^{54} \mathrm{Fe}_{2} \mathrm{O}_{3}$ (Oak Ridge National Laboratory Batch $154891,{ }^{54} \mathrm{Fe}$ $98.37 \%,{ }^{56} \mathrm{Fe} 1.55 \%,{ }^{57} \mathrm{Fe} 0.07 \%,{ }^{58} \mathrm{Fe} 0.008 \%$ ) in a $99: 1$ ratio. The mixture was twice ground under acetone in a mortar and pestle for $30 \mathrm{~min}$. The starting mineral assemblage which consisted of $\sim 50 \mathrm{mg}$ of synthetic fayalite and quartz and $\sim 10 \mathrm{mg}$ of hematite, was ground for $20 \mathrm{~min}$ under acetone to produce a homogeneous mixture.

For each experiment the starting assemblage was loaded with $\sim 15 \mathrm{mg}$ nanopure $\mathrm{H}_{2} \mathrm{O}$ into segments of Au tubing of $3.5 \mathrm{~mm}$ outer-diameter and $0.18 \mathrm{~mm}$ wall thickness. The capsule was then welded shut and checked for leaks by heating at $100^{\circ} \mathrm{C}$ for $30 \mathrm{~min}$ and checking for weight loss. Any capsule that lost weight was incompletely sealed and discarded.

All experiments were performed in a 1-inch diameter piston-cylinder apparatus with $\mathrm{NaCl}$ pressure medium and graphite heater sleeve. A thin piece of Au was placed on top of the capsule to prevent puncture by the thermocouple. Temperature was monitored with $\mathrm{Pt} / \mathrm{Pt}_{90} \mathrm{Rh}_{10}$ thermocouples in contact with the capsule, with no correction for the effect of pressure on emf. The accuracy of the reported temperature is estimated to be $\pm 3{ }^{\circ} \mathrm{C}$. All experiments were brought to a pressure of $7 \mathrm{kbar}$ and then heated to the desired run temperature, where thermal expansion of the assembly brought the pressure to 10 kbar. Pressure was monitored with a Heise gauge and maintained to within 200 bar gauge pressure. Experiments were quenched by cutting power to the apparatus, which resulted in cooling of the experiment to $<50{ }^{\circ} \mathrm{C}$ in $<1$ min (Manning and Boettcher, 1994).

Following each run, the capsules were retrieved, cleaned, and pierced with a needle, releasing water through the hole. The presence of water indicated that the capsule did not leak during the experiment. The run products were then carefully removed and placed in a glass container. After optical inspection using a binocular microscope, magnetite and fayalite were separated 
with a hand magnet. The fayalite was purified by handpicking to a purity of $\sim 100 \%$ and the magnetite was picked to a purity of $>98 \%$.

\subsection{MC-ICPMS analyses}

Experimental products were dissolved in a mixture of hydrofluoric and nitric acids. The solution was then dried down on a hot plate and dissolved again in hydrochloric and nitric acids to make sure dissolution was complete, and then dried again on a hot plate. The final iron solution was picked up in $2 \%$ nitric acid for introduction into the mass spectrometer.

All $\mathrm{Fe}$ isotope ratio measurements were made using a ThermoFinnigan Neptune MC-ICPMS. The instrument has a fixed array of 9 Faraday collectors each with amplifier resistors of $10^{11} \Omega$. Mass interferences from $\mathrm{ArO}^{+}(\sim 2.5 \mathrm{mV}), \mathrm{ArOH}^{+}$ $(<1 \mathrm{mV})$, and $\mathrm{ArN}^{+}(\sim 1.8 \mathrm{~V})$ were resolved from ${ }^{56} \mathrm{Fe}^{+},{ }^{57} \mathrm{Fe}^{+}$ and ${ }^{54} \mathrm{Fe}^{+}$, respectively, by operating at a high mass resolving power of $m / \Delta m>10,000$ (Weyer and Schwieters, 2003). Corrections for instrumental mass bias were obtained by using sample-standard bracketing with peak height matching between sample and standard to better than $5 \%$. Sample and standard were analyzed as $\sim 5 \mathrm{ppm} \mathrm{Fe}$ in $2 \% \mathrm{HNO}_{3}$ aspirated through a Cetac Aridus desolvating nebulizer (samples were run in dry plasma). Samples were analyzed 8 to 10 times with each analysis consisting of 20 cycles of $\sim 4$ second integrations. The starting solutions were checked for ${ }^{52} \mathrm{Cr}^{+}$and in each case the intensity was found to be less than $2 \mathrm{mV}$, which was taken to indicate that ${ }^{54} \mathrm{Cr}^{+}$interference for ${ }^{54} \mathrm{Fe}^{+}$was negligible. The purity of the solutions obviated the need for purification of Fe; potential instrumental mass bias due to inter-element matrix effects was not an issue for these pure solutions containing the analyte $\mathrm{Fe}$. In this study it is the relative differences in $\mathrm{Fe}$ isotope ratios that are of interest. We use the international $\mathrm{Fe}$ isotope standard IRMM-014 as a primary standard in our laboratory, but because we are concerned with relative differences we did not exchange secondary standards with other laboratories as part of this work.

\subsection{Three-isotope exchange method}

In order to establish that our measured fractionation factors represent equilibrium, we used the three-isotope exchange method first described by Matsuhisa et al. (1978). In that study and in those following, fractionation factors between a mineral and water were obtained by adding an isotope spike to one of the reactants. To our knowledge, our study is the first to employ the three-isotope technique to determine an inter-mineral equilibrium fractionation factor directly.

In the context of three $\mathrm{Fe}$ isotopes a condition for equilibrium between two phases $i$ and $j$ is $\alpha_{i-j}^{56 / 54}=\left(\alpha_{i-j}^{57 / 54}\right)^{\gamma}$ where $\alpha_{i-j}^{56 / 54}={ }^{56} R_{i} /{ }^{56} R_{j}$ and the exponent $\gamma$ relating the three isotopes at equilibrium is

$\gamma=\frac{\frac{1}{m_{56}}-\frac{1}{m_{54}}}{\frac{1}{m_{57}}-\frac{1}{m_{54}}}$ where $m$ is the mass of subscripted $\mathrm{Fe}$ isotope. In this case $\gamma=0.67795$. The exponent $\gamma$ is effectively the slope of a fractionation line on a plot of $\delta^{56} \mathrm{Fe}$ vs. $\delta^{57} \mathrm{Fe}$ since $\delta^{56} \mathrm{Fe}_{i}-\delta^{56} \mathrm{Fe}_{j} \sim 10^{3} \ln$ $\alpha_{i-j}^{56 / 54}$ and $\delta^{57} \mathrm{Fe}_{i}-\delta^{57} \mathrm{Fe}_{j} \sim \gamma 10^{3} \ln \alpha_{i-j}^{56 / 54}$. Over the range of isotopic fractionations discussed in this paper these approximations impart only a ppm level of error that is well within analytical uncertainties, e.g. Young et al. (2002).

The principle of the three-isotope exchange method is to replace the terrestrial fractionation line (TFL) having a zero intercept with a secondary fractionation line (SFL) that has a nonzero intercept by use of a spike (Fig. 2). The secondary fractionation line will have the same slope as the TFL but will be displaced from it in proportion to the amount of spike. The equation

$\delta^{56} \mathrm{Fe}_{i}=\gamma \delta^{57} \mathrm{Fe}_{i}+\left(\delta^{56} \mathrm{Fe}_{o}-\gamma \delta^{57} \mathrm{Fe}_{o}\right)$

relates the equilibrium $\mathrm{Fe}$ isotope ratios for phase $i$ on the $\mathrm{SFL}$ where $\delta^{56} \mathrm{Fe}_{o}$ and $\delta^{57} \mathrm{Fe}_{o}$ are the $\delta$ values for the total $\mathrm{Fe}$ comprising the spiked experimental system. The last term in Eq. (2) is the intercept on the Fe three-isotope plot (Fig. 2). At isotopic equilibrium all phases containing Fe must lie on the SFL defined by Eq. (2). The bulk composition of the experimental system, described by $\delta^{56} \mathrm{Fe}_{o}$ and $\delta^{57} \mathrm{Fe}_{o}$, therefore depends on the initial iron fractions of fayalite and spiked hematite.

A series of experiments at a single temperature can fail to yield isotopic equilibrium. In this circumstance the compositions of each partially equilibrated phase, representing varying extents of exchange reaction, will define a straight line extending from the starting composition toward the equilibrium composition on the SFL (Fig. 2). Extrapolation of each line to its intersection with the SFL therefore defines the equilibrium isotopic compositions for the phases of interest. The three-isotope method is thus an especially powerful tool at lower temperatures, where kinetics are slower and equilibrium is seldom attained.

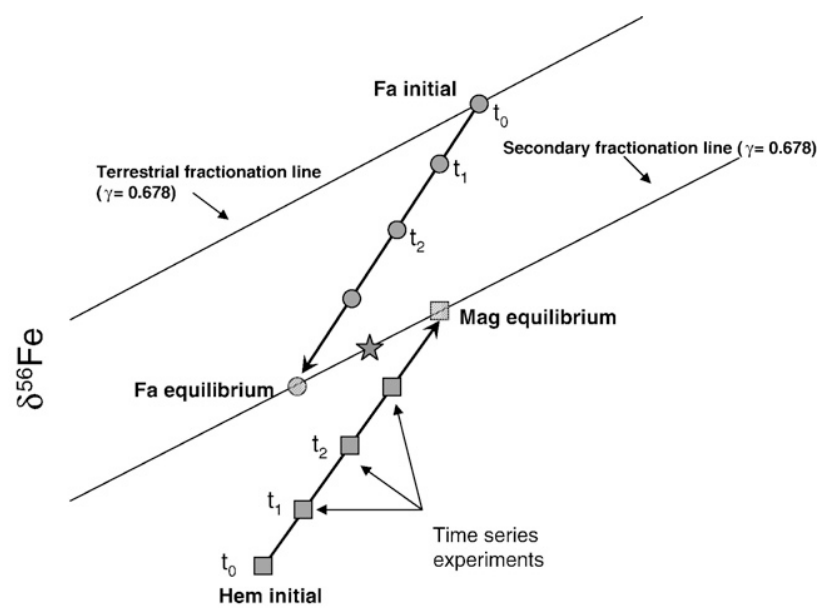

$\delta^{57} \mathrm{Fe}$

Fig. 2. Schematic diagram of the three-isotope exchange method showing the terrestrial fractionation line (TFL) where all natural samples lie, the secondary fractionation line which has the same slope as the TFL but is offset from the TFL due to a ${ }^{54} \mathrm{Fe}$ spike, and a series of experiments with trajectories that intersect the secondary fractionation line. The intersections of the trend lines from the experiments and the secondary fractionation line define the equilibrium isotopic compositions. 
Utilization of the three-isotope method to determine equilibrium fractionations between mineral pairs in the presence of a solvent requires that the minerals do not completely dissolve and then reprecipitate. This is because reprecipitation from a homogeneous medium such as a fluid or melt could yield mineral pairs lying on an SFL but not in exchange equilibrium. This potential problem was avoided in our experiments because the volume of $\mathrm{H}_{2} \mathrm{O}$ present in the capsules was relatively small and mineral solubilities are extremely low at our run conditions. For example, magnetite solubility in $\mathrm{H}_{2} \mathrm{O}$ at $800{ }^{\circ} \mathrm{C}$ and $10 \mathrm{kbar}$ is extremely low, even in the presence of $\mathrm{NaCl}$ (Wykes et al., in press).

A second requirement of the three-isotope method is that no metaphases are present in the runs used to define the equilibrium fractionation factor. Our use of hematite as a starting material thus hinges on complete conversion to magnetite during experiments. Accordingly, we carefully checked all runs to confirm that no hematite was present.

\subsection{Analytical errors and their propagation}

Uncertainties in $\Delta^{57} \mathrm{Fe}_{\mathrm{Mag}-\mathrm{Fa}}$ reported in this study are derived from isotope ratio measurements of fayalite and magnetite from a series of experiments. The method of propagating the uncertainties in individual analyses to the final equilibrium $\Delta^{57} \mathrm{Fe}_{\mathrm{Mag}-\mathrm{Fa}}$ is described below.

The uncertainty in each isotope ratio measurement is the standard error of 8 to 10 analyses of the same sample solution. Analyses of a given mineral for experimental runs of different duration but the same temperature (e.g., 4 analyses of magnetite for experiments at $800{ }^{\circ} \mathrm{C}$ ) are regressed using the "new" York regression (Mahon, 1996). Once a regression and associated uncertainties in slope and intercept are obtained for all magnetite and fayalite products for a given temperature, the equilibrium $\Delta^{57} \mathrm{Fe}_{\mathrm{Mag}-\mathrm{Fa}}=\delta^{57} \mathrm{Fe}_{\mathrm{Mag}}-\delta^{57} \mathrm{Fe}_{\mathrm{Fa}}$ for that temperature is obtained from the difference in the intersection of the magnetite and fayalite regression lines with the secondary fractionation line in three-isotope space. Intersections of $\delta^{57} \mathrm{Fe}$ values are calculated from slopes and intercepts according to the relation

$\delta^{57} \mathrm{Fe}_{\mathrm{Eq}, i}=\frac{-b_{1}+b_{2}}{m_{1}-\gamma}$

where $\delta_{i}{ }^{57} \mathrm{Fe}_{\mathrm{Eq}, i}$ is the projected $\delta^{57} \mathrm{Fe}$ value for mineral $i$ at equilibrium, $m_{1}$ is the slope of the regressed data points for mineral $i, \gamma$ is the slope of the secondary fractionation line, $b_{1}$ is the intercept of the best-fit line through the regressed data points, and $b_{2}$ is the intercept of the secondary fractionation line. Uncertainties in the derived $\Delta^{57} \mathrm{Fe}_{\mathrm{Mag}-\mathrm{Fa}}$ values are obtained from the intersections of the $95 \%$ confidence error envelopes (Ludwig, 1980) for the magnetite and fayalite best-fit lines and the secondary fractionation line. The $\delta^{57} \mathrm{Fe}$ values for the intersection of the SFL and the $95 \%$ confidence error envelope for each best-fit line is calculated using the expression

$$
\begin{aligned}
\delta_{95 \%-\mathrm{SFL}}^{57}= & \left( \pm\left(\sigma_{m_{1}}^{4} \overline{\delta^{57^{2}}}+2 \sigma_{m_{1}}^{2} \overline{\delta^{57}}\left(\gamma-m_{1}\right)\left(b_{2}-b_{1}\right)\right.\right. \\
& +\gamma^{2} \sigma_{b_{1}}^{2}-2 \gamma \sigma_{b_{1}}^{2} m_{1}+b_{2}^{2} \sigma_{m_{1}}^{2}-2 b_{2} b_{1} \sigma_{m_{1}}^{2} \\
& \left.+b_{1}^{2} \sigma_{m_{1}}^{2}+\sigma_{b_{1}}^{2}\left(m_{1}^{2}-\sigma_{m_{1}}^{2}\right)\right)^{1 / 2}-\sigma_{m_{1}}^{2} \overline{\delta^{57}} \\
& \left.+\left(\gamma-m_{1}\right)\left(b_{1}-b_{2}\right)\right) / \gamma^{2}-2 \gamma m_{1}-\sigma_{m_{1}}^{2}+m_{1}^{2}
\end{aligned}
$$

where $\delta_{95 \%-\mathrm{SFL}}^{57}$ is the $\delta^{57} \mathrm{Fe}$ value for the intersection of the $95 \%$

\begin{tabular}{|c|c|c|c|c|c|c|c|}
\hline Name & Mineral & $\begin{array}{l}\text { Temp } \\
\left({ }^{\circ} \mathrm{C}\right)\end{array}$ & $\begin{array}{l}\text { Time } \\
\text { (h) }\end{array}$ & $\begin{array}{l}\delta^{56} \mathrm{Fe} \\
(\% 0)\end{array}$ & $\begin{array}{l}\delta^{57} \mathrm{Fe} \\
(\% 0)\end{array}$ & $\delta^{56} \mathrm{Fe}$ & \% Exchange * \\
\hline Start & Fayalite & - & - & $0.64(1)$ & $0.95(6)$ & 0.00 & - \\
\hline Start & Hematite & - & - & $-12.63(4)$ & $-12.32(7)$ & -4.29 & - \\
\hline Start & Hematite3 & - & - & $-11.13(2)$ & $-10.75(3)$ & -3.85 & - \\
\hline Start & Hematite4 & - & - & $-10.88(1)$ & $-10.57(1)$ & -3.72 & - \\
\hline QFM18 & Fayalite & 600 & 24 & $-0.04(1)$ & $0.21(2)$ & -0.19 & 25 \\
\hline QFM18 & Magnetite & 600 & 24 & $-3.29(2)$ & $-2.93(3)$ & -1.30 & 82 \\
\hline QFM21 & Fayalite & 600 & 48 & $-1.01(2)$ & $-0.77(3)$ & -0.49 & 45 \\
\hline QFM21 & Magnetite & 600 & 48 & $-4.60(2)$ & $-4.32(2)$ & -1.68 & 79 \\
\hline QFM22 & Fayalite & 600 & 73 & $-0.97(1)$ & $-0.73(2)$ & -0.48 & 51 \\
\hline QFM22 & Magnetite & 600 & 73 & $-3.76(1)$ & $-3.44(2)$ & -1.41 & 83 \\
\hline QFM23 & Fayalite & 700 & 24 & $-1.75(1)$ & $-1.49(1)$ & -0.74 & 65 \\
\hline QFM23 & Magnetite & 700 & 24 & $-4.04(1)$ & $-3.71(1)$ & -1.52 & 85 \\
\hline QFM24 & Fayalite & 700 & 48 & $-0.88(1)$ & $-0.62(2)$ & -0.46 & 46 \\
\hline QFM24 & Magnetite & 700 & 48 & $-4.15(1)$ & $-3.84(2)$ & -1.55 & 80 \\
\hline QFM25 & Fayalite & 700 & 72 & $-1.68(1)$ & $-1.45(2)$ & -0.70 & 65 \\
\hline QFM25 & Magnetite & 700 & 72 & $-3.80(1)$ & $-3.47(1)$ & -1.45 & 86 \\
\hline QFM12 & Fayalite & 800 & 6 & $-0.88(2)$ & $-0.61(3)$ & -0.47 & 48 \\
\hline QFM12 & Magnetite & 800 & 6 & $-4.63(2)$ & $-4.31(2)$ & -1.51 & 82 \\
\hline QFM13 & Fayalite & 800 & 12 & $-1.33(1)$ & $-1.08(2)$ & -0.60 & 78 \\
\hline QFM13 & Magnetite & 800 & 12 & $-2.58(1)$ & $-2.25(2)$ & -0.93 & 95 \\
\hline QFM10 & Fayalite & 800 & 24 & $-2.26(2)$ & $-1.99(4)$ & -0.91 & 94 \\
\hline QFM10 & Magnetite & 800 & 24 & $-2.53(2)$ & $-2.20(4)$ & -1.04 & 98 \\
\hline QFM8 & Fayalite & 800 & 49 & $-2.37(2)$ & $-2.11(3)$ & -0.93 & 100 \\
\hline QFM8 & Magnetite & 800 & 49 & $-2.12(2)$ & $-1.76(4)$ & -0.92 & 100 \\
\hline
\end{tabular}
envelope and the SFL ( $+/-$ accounts for the two boundaries of the

Table 1

Experimental results

* Percent exchange $\left(\left(\delta-\delta_{0}\right) /\left(\delta_{\mathrm{eq}}-\delta_{0}\right) * 100\right)$ refers to the degree at which the mineral has come to equilibrium in the particular experiment. It is not reproducible and depends on experimental conditions. 
envelope), $\sigma_{\mathrm{b} 1}$ is the uncertainty (se) in $b_{1}, \sigma_{m 1}$ is the uncertainty in $m_{1}$, and $\delta^{57}$ is the centroid $\delta^{57} \mathrm{Fe}$ value for the regressed data. Standard errors for the equilibrium $\delta^{57} \mathrm{Fe}$ values for magnetite and fayalite obtained by extrapolation are calculated by dividing the $95 \%$ uncertainties in intersections by 2 (assuming 95\% confidence limits are $\sim 2 \mathrm{se}$ ). These standard errors for the equilibrium $\delta^{57} \mathrm{Fe}_{\mathrm{Mag}}$ and $\delta^{57} \mathrm{Fe}_{\mathrm{Fa}}$ values are then propagated through to the final $\Delta^{57} \mathrm{Fe}_{\mathrm{Mag}-\mathrm{Fa}}$ in the usual way (square root of sum of squares). The standard errors reported below for the $\Delta^{57} \mathrm{Fe}_{\mathrm{Mag}-\mathrm{Fa}}$ at each temperature were determined in this manner (reported as 2 se). Finally, the values of $\Delta^{57} \mathrm{Fe}_{\mathrm{Mag}-\mathrm{Fa}}$ at each temperature were regressed (Mahon, 1996) in order to obtain the final equation for the temperature dependence of $\Delta \Delta^{57} \mathrm{Fe}_{\mathrm{Mag}-\mathrm{Fa}}$ with associated uncertainty.

\section{Results}

Results of the experiments at $600{ }^{\circ} \mathrm{C}, 700{ }^{\circ} \mathrm{C}$ and $800{ }^{\circ} \mathrm{C}$ are given in Table 1, along with the starting compositions of the hematite and fayalite. Each isothermal set of experiments was conducted with a new batch of spiked hematite standard, leading to different hematite starting compositions. The experiments at $700{ }^{\circ} \mathrm{C}$ and $800{ }^{\circ} \mathrm{C}$ were conducted at $10 \mathrm{kbar}$. At $600{ }^{\circ} \mathrm{C}$ the pressure was dropped to $9.5 \mathrm{kbar}$ to ensure fayalite+ quartz stability relative to ferrosilite (Bohlen et al., 1980).

\subsection{Textures}

Product mineral assemblages and textures were examined by optical microscopy and scanning electron microscopy (SEM). Fayalite, magnetite and quartz were the only minerals present in the run products. No evidence for hematite was found during optical inspection at low magnification. SEM petrography (Fig. 3) showed that magnetite occurs in all run products as fine-grained $(\sim 1-2 \mu \mathrm{m})$ matted clusters of octahedra interspersed between fayalite and quartz. Quartz recrystallized to large $(\sim 10-30 \mu \mathrm{m})$ equant crystals. Fayalite forms intermediate $(\sim 5-10 \mu \mathrm{m})$ subhedral prisms. The run-product textures therefore suggest that conversion of hematite to magnetite occurred rapidly $(<6 \mathrm{~h})$. Comparison of run products from the $800^{\circ} \mathrm{C}$ experiments of 6 and $48 \mathrm{~h}$ duration (Fig. 3a, b) revealed similar textures and grain sizes, indicating insignificant grain annealing or textural modification from 6 to $48 \mathrm{~h}$, perhaps owing to the relatively low mineral solubilities in $\mathrm{H}_{2} \mathrm{O}$. These observations establish that the equilibrium mineral assemblage was rapidly attained in all experiments. As discussed below, isotopic exchange equilibrium among these phases occurred more slowly, highlighting the utility of the threeisotope method in establishing equilibrium in piston-cylinder experiments.

\section{2. $800{ }^{\circ} \mathrm{C}$}

Experiments were performed at $800{ }^{\circ} \mathrm{C}$ (Fig. 4a, b) for 6, 12, 24 , and $49 \mathrm{~h}$. Fayalite and magnetite from the $49 \mathrm{~h}$ run lie on the SFL for this temperature in three-isotope space (Fig. 4), indicating close approach to exchange equilibrium. The inferred equilibrium $\Delta^{57} \mathrm{Fe}_{\mathrm{Mag}-\mathrm{Fa}}$ at $800{ }^{\circ} \mathrm{C}$ is $0.28+/-0.04 \%$ ( 2 se). Fig. 5 shows the
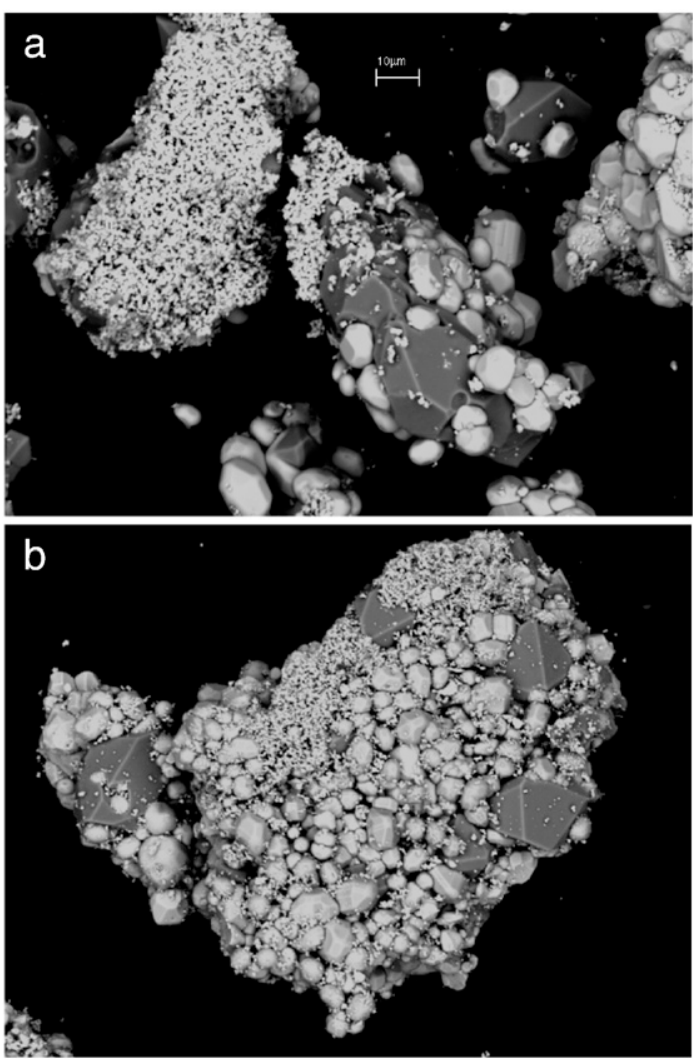

Fig. 3. Backscattered electron images showing the crystal faces and textures of experimental run products grown at $800{ }^{\circ} \mathrm{C}$ for $6 \mathrm{~h}$ (a) and $48 \mathrm{~h}$ (b). The largest crystals are quartz (dark grey), followed by fayalite (light grey) and then magnetite (white). The scale bar is the same in both images.

secondary fractionation lines in detail at each temperature to highlight intersections with the $95 \%$ confidence error envelopes discussed above.

\section{3. $700{ }^{\circ} \mathrm{C}$ and $600{ }^{\circ} \mathrm{C}$}

Experiments were performed at $700{ }^{\circ} \mathrm{C}$ (Fig. 4c, d) and $600{ }^{\circ} \mathrm{C}$ (Fig. 4e, f ) for 24,48 , and $\sim 72 \mathrm{~h}$. None of these experiments attained isotopic equilibrium, as indicated by the fact that none of the experimental products at these temperatures have isotopic compositions on the secondary fractionation lines. The equilibrium $\mathrm{Fe}$ isotope ratios of magnetite and fayalite at these temperatures were therefore obtained by extrapolation to the respective SFLs. Extrapolation of the regressed data to the SFLs at each temperature yielded $\Delta^{57} \mathrm{Fe}_{\mathrm{Mag}-\mathrm{Fa}}$ values of $0.31+/$ $-0.08 \%$ at $700{ }^{\circ} \mathrm{C}$ and $0.38+/-0.06 \%$ at $600{ }^{\circ} \mathrm{C}$.

\subsection{Temperature dependence of equilibrium $\mathrm{Fe}$ isotope exchange}

The experimentally-determined magnetite-fayalite fractionations are plotted as a function of temperature in Fig. 6. The experimental values are compared to the theoretical curves for olivine and magnetite fractionation from Polyakov and Mineev (2000), Polyakov et al. (2007), and Mineev et al. (2007). When 

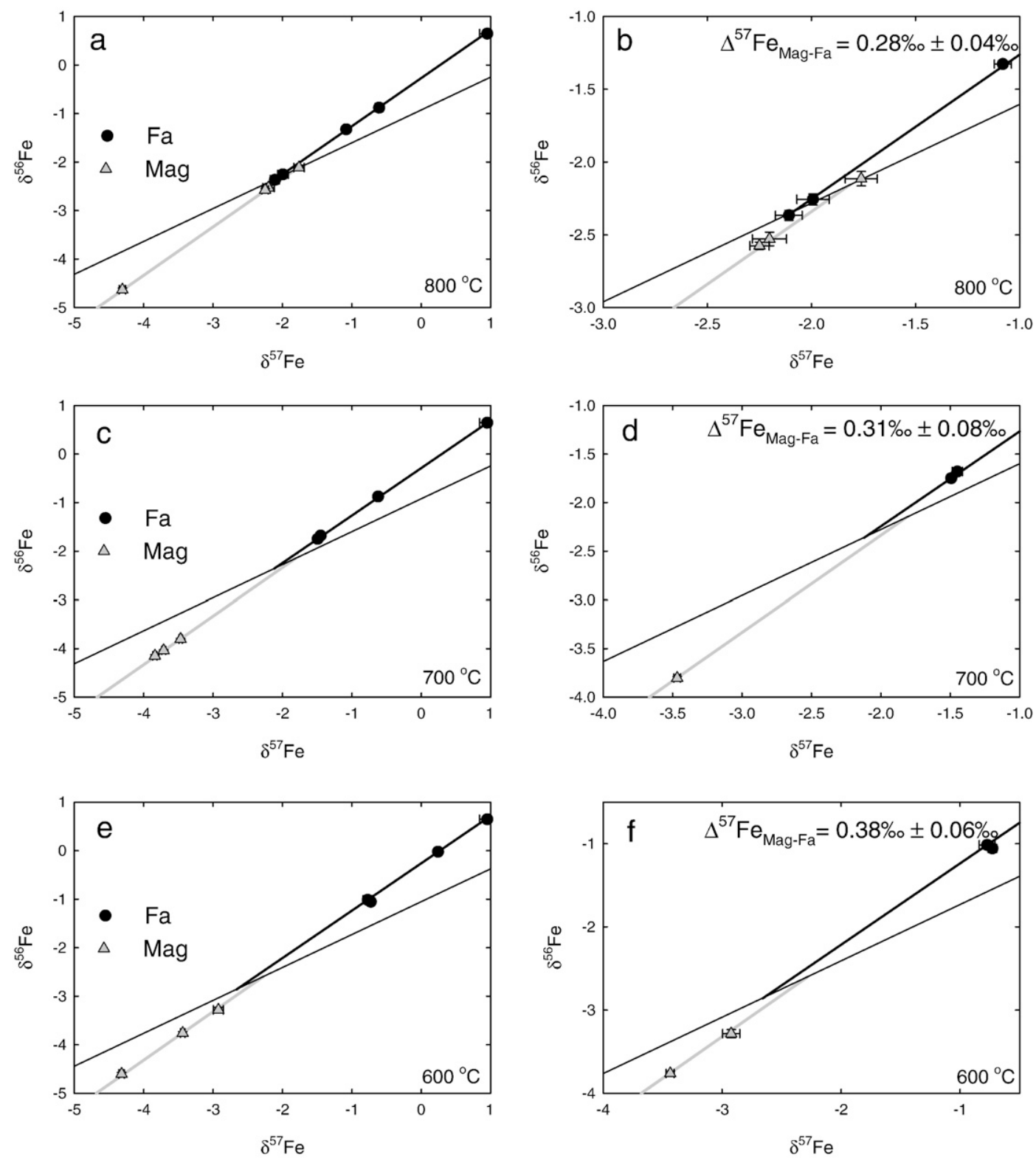

Fig. 4. Experimental results at $800^{\circ} \mathrm{C}(\mathrm{a}, \mathrm{b}), 700^{\circ} \mathrm{C}(\mathrm{c}, \mathrm{d})$, and $600^{\circ} \mathrm{C}(\mathrm{e}, \mathrm{f})$. Fig. $4 \mathrm{~b}$, d, and f are close-ups of a, c, and e respectively. The black circles are fayalite, and the gray triangles are magnetite. The minerals at $800^{\circ} \mathrm{C}$ have come to equilibrium on a secondary fractionation line determined by the bulk Fe isotopic composition of the system. Error bars (2 se) are shown where they are larger than symbol sizes. The best-fit line was calculated using the new York regression (Mahon, 1996). See text for more details.

the data are regressed (Mahon, 1996) by forcing the best-fit line through the origin, the temperature-dependence of the magnetite-fayalite fractionation factor is

$$
\Delta^{57} \mathrm{Fe}_{\mathrm{Mag}-\mathrm{Fa}}=0.30(+/-0.024) \times 10^{6} / T^{2}
$$

where the uncertainty is at the 2 se level.

\section{Discussion}

\subsection{Comparison to theoretical predictions}

Recent theoretical studies have predicted the magnitude and direction of iron isotopic fractionation between various phases and molecules at a range of temperatures. Equilibrium isotopic fractionations are caused by sensitivities of vibrational frequencies to isotopic substitutions. The vibrational frequencies for modes of vibration in a material can be calculated with first-principles quantum mechanical methods (e.g., Jarzecki et al., 2004). Alternatively, Mössbauer spectroscopy or Inelastic Nuclear Resonant X-ray Scattering (INRXS) can be used to obtain vibrational properties of ${ }^{57} \mathrm{Fe}$ within minerals, and then the vibrational frequencies for other isotopes can be calculated (e.g., Polyakov and Mineev, 2000). The theoretical predictions can be extended over a range of temperature conditions so as to give the theoretical fractionation factor for two minerals as a function of temperature. These predictions come in the form of ratios of reduced (i.e., vibrational) partition function ratios for 

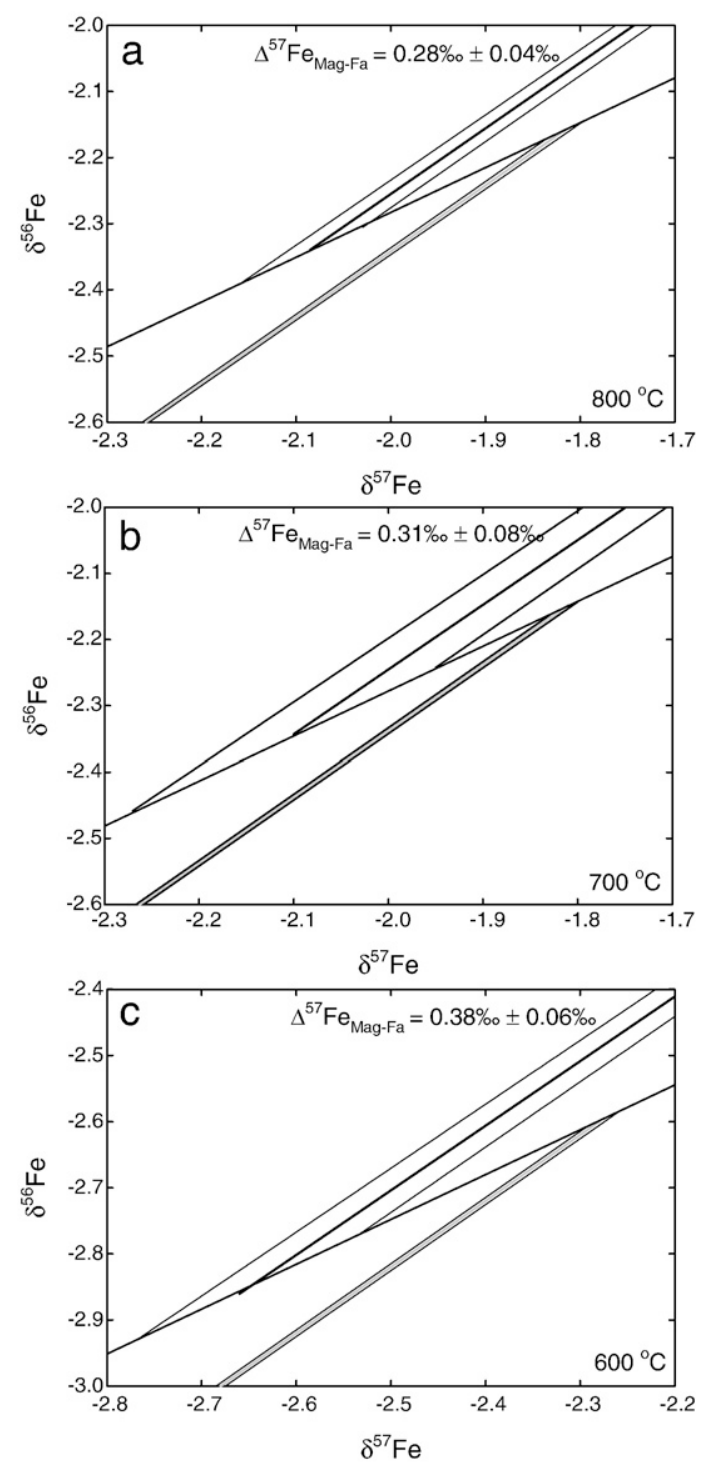

Fig. 5. Intersections between secondary fractionation lines and $95 \%$ confidence error envelopes for best fits to fayalite and magnetite data in $\mathrm{Fe}$ three-isotope space. Best-fit lines are shown for experiments performed at $800{ }^{\circ} \mathrm{C}$ (a), $700{ }^{\circ} \mathrm{C}$ (b), and $600{ }^{\circ} \mathrm{C}$ (c). Fits to fayalite are shown as heavy black lines. Fits to magnetite are shown as heavy grey lines. Error envelopes are shown as thinner lines. Data points are out of the field of view.

phases $i$, relative to some common reference state for the element of interest. These reduced partition function ratios $\beta_{i}$, also referred to as $\beta$-factors, define the fractionation factor according to the relation $\ln \alpha_{i-j}=\ln \beta_{i}-\ln \beta_{j}$ where $\alpha_{i j}$ is the equilibrium isotope fractionation factor between phases $i$ and $j$.

The most important determining factor for ${ }^{56} \mathrm{Fe} /{ }^{54} \mathrm{Fe}$ (or ${ }^{57} \mathrm{Fe} /{ }^{54} \mathrm{Fe}$ ) fractionation is bond stiffness, because bond strengths determine vibrational frequencies that in turn determine internal energies. Higher oxidation state and lower coordination number will lead to stiffer bonds that concentrate heavy isotopes in order to minimize the total vibrational energy of the system. Fayalite, $\mathrm{Fe}^{\mathrm{VI}}{ }_{2} \mathrm{Si}^{\mathrm{IV}} \mathrm{O}_{4}$, incorporates only ferrous $\left(\mathrm{Fe}^{2+}\right)$ iron into its structure and always in octahedral coordination, whereas magnetite, $\left(\mathrm{Fe}^{3+}\right)^{\mathrm{IV}}\left(\mathrm{Fe}^{3+} \mathrm{Fe}^{2+}\right)^{\mathrm{VI}} \mathrm{O}_{4}$, incorporates both ferrous and ferric iron into its structure, in a 1:2 ratio, and with half of the ferric iron in tetrahedral coordination. Therefore, the prediction is that magnetite in equilibrium with fayalite will concentrate more of the heavy isotope and have a greater $\delta^{57} \mathrm{Fe}$ value than fayalite at equilibrium.

Polyakov and Mineev (2000) published $\beta$-factors for olivine and magnetite based on Mössbauer spectroscopy data. The authors predict an enrichment of heavy iron isotopes in $\mathrm{Fe}^{3+}$ bearing minerals. The $\beta$-factors for magnetite were recently revised (Polyakov et al., 2007; Mineev et al., 2007) in view of new INRXS data and new Mössbauer data. (The two studies differ due to slight differences in the oxidation state of $\mathrm{Fe}$ in the magnetite measured.) Our experimentally-determined temperature-dependent $\Delta^{57} \mathrm{Fe}_{\mathrm{Mag}-\mathrm{Fa}}$ equation falls within a range defined by the two most recent theoretical studies (Fig. 6). The close match between the experimental results and the theoretical results is apparently due in part to the well-characterized differences in the crystal chemical environment of $\mathrm{Fe}$ in magnetite and fayalite.

\subsection{Applications to natural systems}

Recent work (Poitrasson and Freydier, 2005; Schoenberg and von Blanckenburg, 2006) has suggested that the most evolved magmas show the heaviest iron isotopic signatures. This trend towards high ${ }^{57} \mathrm{Fe} /{ }^{54} \mathrm{Fe}$ isotope compositions with magma evolution could be due to open-system behavior, latestage fluid exsolution processes, or fractional crystallization. With the data presented in this study, it is possible to assess the direction and magnitude of changes in $\delta^{57} \mathrm{Fe}$ attending differentiation by fractional crystallization if the fractionating assemblage includes a spinel phase (e.g., magnetite) because it is the difference in coordination between tetrahedral and octahedral Fe that drives the fractionation and $\mathrm{Fe}$ is likely to be octahedrally coordinated in silicate melts.

One can apply the equilibrium fractionation factor determined in this work to estimate $\mathrm{Fe}$ isotope fractionation attending fractional crystallization of magnetite by treating fractional crystallization as a Rayleigh process. Grove and Kinzler (1986) present a model for fractional crystallization of an andesitic lava with a fractionating assemblage that includes magnetite. Based

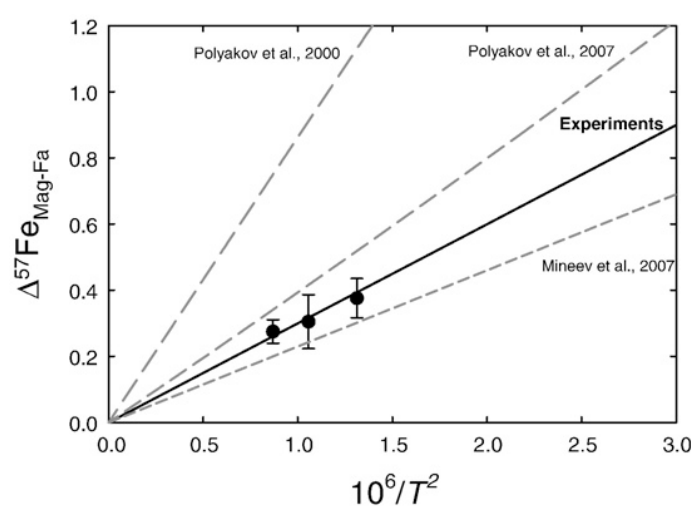

Fig. 6. Experimental magnetite-fayalite Fe isotope fractionation data plotted as a function of temperature along with theoretical predictions for the fractionation (see text). Error bars shown are 2 se. 
on their model, approximately $80 \%$ of the Fe lost from the melt is extracted as magnetite. The relevant equation for Rayleigh fractionation is

${ }^{57} \mathrm{R} /{ }^{57} \mathrm{R}_{i}=F^{\alpha-1}$,

where ${ }^{57} \mathrm{R}$ is the ${ }^{57} \mathrm{Fe} /{ }^{54} \mathrm{Fe}$ isotopic ratio of the remaining melt, ${ }^{57} \mathrm{R}_{i}$ represents the initial isotope ratio of the melt, $F$ is the fraction of liquid remaining and $\alpha_{\text {solid-melt }}$ is the fractionation factor between fractionating solids and melt. Based on the model of Grove and Kinzler, $F$ varies from 1 to $\sim 0.33$ for evolving andesite magmas when magnetite dominates the fractionating assemblage for Fe. For this simple calculation we use the fractionation between magnetite and fayalite as a model for the fractionation between magnetite and melt. Since $80 \%$ of the $\mathrm{Fe}$ fractionation occurs by magnetite removal, we dilute the magnetite-melt fractionation factor to simulate the bulk solidmelt fractionation factor. The dilution, whereby $\alpha_{\text {solid-melt }}=0.8$ $\alpha_{\mathrm{Mag}-\mathrm{Fa}}$, assumes all other fractionation factors between crystallizing Fe-bearing minerals and melt are unity. Fig. 7 shows that for temperatures of $1000^{\circ} \mathrm{C}$ and $1100{ }^{\circ} \mathrm{C}$ an andesitic magma series affected by magnetite fractionation could exhibit shifts in ${ }^{57} \mathrm{Fe} /{ }^{54} \mathrm{Fe}$ of up to $0.27 \%$. This is a measurable amount of $\mathrm{Fe}$ isotope fractionation given the precision with which ${ }^{57} \mathrm{Fe} /{ }^{54} \mathrm{Fe}$ is measured by MC-ICPMS $(2 \sigma<0.05 \%)$.

The trend observed in the above simplistic model would predict that evolved magmas would become lighter during fractional crystallization if magnetite was a major fractionating phase. Since this is not what is observed in the literature to date, one concludes that magmatic differentiation in the rocks studied thus far did not occur by fractional crystallization of tetrahedrally coordinated $\mathrm{Fe}$. Alternatives are that partial melting and/or metasomatic processes dominated the $\mathrm{Fe}$ isotope systematics (Williams et al., 2004).

Nonetheless, Fe isotopic signatures of magnetite fractionation should exist in differentiation sequences in which magnetite played an important role. Crystallization of magnetite is sensitive

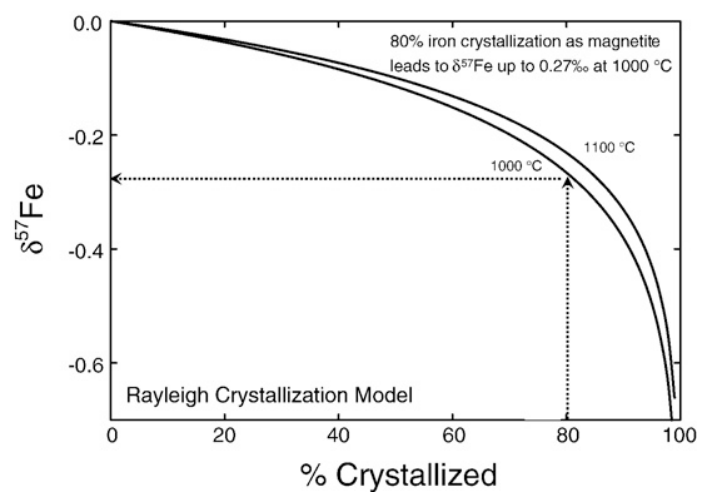

Fig. 7. Rayleigh fractionation model for $\mathrm{Fe}$ isotope fractionation attending differentiation of an andesite magma by fractional crystallization of magnetite. In this calculation $80 \%$ of the Fe present as solid is in the form of magnetite (see text). Using the experimental fractionation factor between fayalite and magnetite determined in this study as a proxy for silicate melt-magnetite fractionation, the prediction is that an andesite liquid line of descent will exhibit a change in ${ }^{57} \mathrm{Fe} /{ }^{54} \mathrm{Fe}$ of $0.27 \%$ at $1000{ }^{\circ} \mathrm{C}$. to the oxygen fugacity of the melts and under the right oxidation conditions, magnetite will be the dominant Fe-bearing fractionating phase. The Skaergaard Intrusion would provide a good test of the predicted decrease in ${ }^{57} \mathrm{Fe} /{ }^{54} \mathrm{Fe}$ with differentiation if the processes responsible for magnetite fractional crystallization occurred in quasistatic isotopic equilibrium and under closedsystem conditions (e.g., Fig. 7). The differentiation sequence of the Skaergaard is thought to have been characterized by the appearance of magnetite in the final stages of differentiation (Hunter and Sparks, 1987). Magnetite crystallization strongly depleted the total $\mathrm{Fe}$ of the melt along a classical tholeiitic liquid line of descent. The crystallization temperature of magnetite is thought to be between $1000^{\circ} \mathrm{C}$ and $1100^{\circ} \mathrm{C}$, suggesting that shifts in $\delta^{57} \mathrm{Fe}$ in the Skaergaard sequence should be on the order of 0.2 to $0.3 \%$.

Fractionation of $\mathrm{Fe}$ isotopes between magnetite and fayalite could be a useful thermometer for rocks containing these minerals. The uncertainty in the temperature from this calibration is

$\sigma_{T}=500 \sqrt{\frac{\sigma_{M}^{2}}{\Delta_{\mathrm{Mag}-\mathrm{Fa}}^{57} M}+\frac{M \sigma_{\Delta_{\mathrm{Mag}-\mathrm{Fa}}^{2}}^{2}}{\left(\Delta_{\mathrm{Mag}-\mathrm{Fa}}^{57}\right)^{3}}}$

where $M$ is the calibration slope ( 0.30$), \sigma_{M}$ is the standard error in the slope $(+/-0.012), \Delta_{\mathrm{Mag}-\mathrm{Fa}}^{57}$ is the measured fractionation, and $\sigma_{\Delta_{\mathrm{Mag} F \mathrm{Fa}}^{57}}$ is the uncertainty in the measured fractionation. Typical uncertainties in measured ${ }^{57} \mathrm{Fe} /{ }^{54} \mathrm{Fe}$ in minerals (e.g., $+/-0.02 \%$ 2 se) suggest that the resolution of this technique would be on the order of $\pm 40{ }^{\circ} \mathrm{C}(1 \mathrm{se})$ at magmatic temperatures. The thermometer has the advantage that it relies only on isotopic equilibrium between these two phases.

\subsection{Oxygen fugacity}

Although Fe oxidation state and oxygen fugacity are linked, there are complications in the simple statement that ferrous iron should be found in reduced environments and ferric iron in oxidized environments. Some minerals incorporate $\mathrm{Fe}^{3+}$ into their structures (e.g., spinel), while others will exclude $\mathrm{Fe}^{3+}$ even under highly oxidizing conditions (e.g., olivine). The differences in structures that accommodate ferrous iron or ferric iron are more complicated than the simple loss or gain of an electron. The addition of $\mathrm{Fe}^{3+}$ can replace a trivalent cation, such as $\mathrm{Al}$, and many times requires a coupled substitution or the creation of defects. For these reasons, although the iron oxidation state in crystalline materials can be influenced by the overall environmental oxidation state, the relationship is apt to be less straightforward than in, for example, aqueous solutions or melts.

At each temperature in our experiments the oxygen fugacity is known since the stable assemblage in the runs comprise the quartz-fayalite-magnetite (QFM) oxygen fugacity buffer. Williams et al. (2004) presented iron isotope data for a suite of mantle minerals in an attempt to determine whether iron isotopic fractionation could be used as a tracer for changes in mantle oxidation state. The authors found lower ${ }^{57} \mathrm{Fe} /{ }^{54} \mathrm{Fe}$ for mantle spinels with higher oxygen fugacity and an inverse 
correlation between ${ }^{57} \mathrm{Fe} /{ }^{54} \mathrm{Fe}$ and $\mathrm{Fe}^{3+}$ concentration in spinel. These findings apparently contradict expectations based on bond strength; the expectation is that higher charged $\mathrm{Fe}^{3+}$ will result in stiffer bonds and therefore greater ${ }^{57} \mathrm{Fe} /{ }^{54} \mathrm{Fe}$. Williams et al. (2004) attribute their results to open-system processes. More experiments will be required to investigate $\mathrm{Fe}$ isotope fractionation involving spinels other than magnetite and the effect of oxygen fugacity on iron isotope fractionation in different geochemical settings.

\section{Conclusions}

This work shows that the three-isotope method is an effective means of establishing that isotopic equilibrium has been attained in a piston-cylinder experiment. Using this technique we find a temperature-dependent $\mathrm{Fe}$ isotope fractionation between fayalite and magnetite at magmatic and high-grade metamorphic temperatures that can be used as a quantitative thermometer in rocks containing these minerals. Agreement between the experimental result reported here and previous predictions based on ab initio calculations and spectroscopy validates our understanding of the underlying controls for $\mathrm{Fe}$ isotope fractionation in mineral phases. In particular, $\mathrm{Fe}$ isotope fractionation between magnetite and fayalite is relatively large because of the presence of $\mathrm{Fe}$ in tetrahedral coordination in magnetite. Changes in $\mathrm{Fe}$ isotope ratios are expected to be evident in magmatic differentiation sequences where magnetite was a fractionating phase. In order to understand the meaning of small but significant differences in $\mathrm{Fe}$ isotope ratios among minerals representing differentiated planetary materials (e.g., samples of Earth's mantle) the mechanisms of high- $T$ Fe isotope fractionation must be quantified. The experimental approach taken here shows considerable promise for establishing equilibrium fractionation factors in high- $T$ and high- $P$ experiments.

\section{Acknowledgements}

The authors thank Bob Newton for endless help with the piston-cylinder experiments and Edwin Schauble for insightful discussions. The paper was improved following thoughtful reviews by Helen Williams and Stefan Weyer. This work was supported by NSF (EAR0711411) and a grant from the NASA Astrobiology Institute (UCLA).

\section{References}

Beard, B.L., Johnson, C.M., 2004. Inter-mineral Fe isotope variations in mantlederived rocks and implications for the Fe geochemical cycle. Geochim. Cosmochim. Acta 68, 4727-4743.

Beard, B.L., Johnson, C.M., 1999. High precision iron isotope measurements of terrestrial and lunar materials. Geochim. Cosmochim. Acta 63, 1653-1660.

Bohlen, S.R., Essene, E.J., Boettcher, A.L., 1980. Reinvestigation and application of olivine-quartz-orthopyroxene barometry. Earth Planet. Sci. Lett. $47,1-10$.
Grove, T.L., Kinzler, R.J., 1986. Petrogenesis of andesites. Annu. Rev. Earth Planet. Sci. 14, 417-454.

Hunter, R.H., Sparks, R.S.J., 1987. The differentiation of the Skaergaard intrusion. Contrib. Mineral. Petrol. 95, 451-461.

Jarzecki, A.A., Anbar, A.D., Spiro, T.G., 2004. DFT analysis of Fe(H2O)(6)(3+) and $\mathrm{Fe}(\mathrm{H} 2 \mathrm{O})(6)(2+)$ structure and vibrations; implications for isotope fractionation. J. Phys. Chem. A 108, 2726-2732.

Ludwig, K.R., 1980. Calculation of uncertainties of U-PB isotope data. Earth Planet. Sci. Lett. 46, 212-220.

Mahon, K.I., 1996. The new "York" regression: application of an improved statistical method to geochemistry. Int. Geol. Rev. 38, 293-303.

Manning, C.E., Boettcher, S.L., 1994. Rapid-quench hydrothermal experiments at mantle pressures and temperatures. Am. Mineral. 79, 1153-1158.

Matsuhisa, J., Goldsmith, J.R., Clayton, R.N., 1978. Mechanisms of hydrothermal crystallisation of quartz at $250^{\circ} \mathrm{C}$ and $15 \mathrm{kbar}$. Geochim. Cosmochim. Acta 42, $173-182$.

Mineev, S.D., Polyakov, V.B., Permyakov, Y.V., 2007. Equilibrium iron isotope fractionation factors for magnetite from Mössbauer spectroscopy and inelastic nuclear resonant X-ray scattering data. Geochim. Cosmochim. Acta 71 A669 Suppl.

Poitrasson, F., Freydier, R., 2005. Heavy iron isotope composition of granites determined by high resolution MC-ICP-MS. Chem. Geol. 222, 132-147.

Poitrasson, F., Halliday, A.N., Lee, D.C., Levasseur, S., Teutsch, N., 2004. Iron isotope differences between Earth, Moon, Mars and Vesta as possible records of contrasted accretion mechanisms. Earth Planet. Sci. Lett. 223, 253-266.

Polyakov, V.B., Clayton, R.N., Horita, J., Mineev, S.D., 2007. Equilibrium iron isotope fractionation factors of minerals: reevaluation from the data of nuclear inelastic resonant X-ray scattering and Mössbauer spectroscopy. Geochim. Cosmochim. Acta 71, 3833-3846.

Polyakov, V.B., Mineev, S.D., 2000. The use of Mössbauer spectroscopy in stable isotope geochemistry. Geochim. Cosmochim. Acta 64, 849-865.

Roskosz, M., Luais, B., Watson, H.C., Toplis, M.J., Alexander, C.M.O., Mysen, B.O., 2006. Experimental quantification of the fractionation of Fe isotopes during metal segregation from a silicate melt. Earth Planet. Sci. Lett. 248, $851-867$.

Schoenberg, R., von Blanckenburg, F., 2006. Modes of planetary-scale Fe isotope fractionation. Earth Planet. Sci. Lett. 252, 342-359.

Schuessler, J.A., Schoenberg, R., Behrens, H., von Blanckenburg, F., 2007. The experimental calibration of the iron isotope fractionation factor between pyrrhotite and peralkaline rhyolitic melt. Geochim. Cosmochim. Acta 71, 417-433.

Weyer, S., Schwieters, J.B., 2003. High precision Fe isotope measurements with high mass resolution MC-ICPMS. Int. J. Mass Spectrom. 226, 355-368.

Williams, H.M., McCammon, C.A., Peslier, A.H., Halliday, A.N., Teutsch, N., Levasseur, S., Burg, J.P., 2004. Iron isotope fractionation and the oxygen fugacity of the mantle. Science 304, 1656-1659.

Williams, H.M., Peslier, A.H., McCammon, C., Halliday, A.N., Levasseur, S., Teutsch, N., Burg, J.P., 2005. Systematic iron isotope variations in mantle rocks and minerals: the effects of partial melting and oxygen fugacity. Earth Planet. Sci. Lett. 235, 435-452.

Wykes, J. L., Newton, R. C., and Manning, C. E., in press. Solubility of andradite, $\mathrm{Ca} 3 \mathrm{Fe} 2 \mathrm{Si} 3 \mathrm{O} 12$, in a 10 mole $\% \mathrm{NaCl}$ solution at $800{ }^{\circ} \mathrm{C}$ and $10 \mathrm{kbar}$ : implications for the metasomatic origin of grandite garnet in skarns and calc-silicate granulites. American Mineralogist.

Young, E.D., Galy, A., Nagahara, H., 2002. Kinetic and equilibrium massdependent isotope fractionation laws in nature and their geochemical and cosmochemical significance. Geochim. Cosmochim. Acta 66, 1095-1104.

Zhu, X.K., Guo, Y., Williams, R.J.P., O’Nions, R.K., Matthews, A., Belshaw, N.S., Canters, G.W., de Waal, E.C., Weser, U., Burgess, B.K., Salvato, B., 2002. Mass fractionation processes of transition metal isotopes. Earth Planet. Sci. Lett. 200, 47-62.

Zhu, X.K., Guo, Y., O’Nions, R.K., Young, E.D., Ash, R.D., 2001. Isotopic homogeneity of iron in the solar nebula. Nature 412, 311-313. 